\title{
Influence of Climatic Cycles on Properties of Leadfree Solders
}

\author{
M. Tučan, P. Žák
}

\begin{abstract}
This paper presents complex climatic tests performed in the laboratory of climatechnology of the Department of Electrotechnology. More specifically, it presents the results of climatic shocks administered to specimens of Sn-Pb and leadfree solders, and compares the results.

While the experimental results are negative regarding the use of electrical resistance as a method for tracking degradation of the joints, the research has provided a large number of specimens that can be examined for structural changes in the solder after climatic stress.
\end{abstract}

Keywords: climatic tests, shocks, leadfree solder.

\section{Leadfree challenges}

Leadfree soldering, compulsory today for most of the electronics industry, brings many challenges in its implementation. Apart from problems such as tin corrosion and faster oxidation due to higher temperature, which appear in the production phase, there is the matter of the long-term behavior of leadfree solders.

Classical $\mathrm{Sn}-\mathrm{Pb}$ solder was used for decades. A large sum of knowledge was accumulated about its properties in various conditions and climates. Based on this knowledge, it is possible to make at least a rough prediction of the behavior of soldered joints in adverse conditions.

However, we have only limited knowledge of the long-term properties of the technologies which have replaced $\mathrm{Sn}-\mathrm{Pb}$ solders, be it leadfree soldering, lowtemperature soldering or the use of electrically conductive adhesives.

This lack of experience prevents the use of such technologies in many important fields. The most prominent of these are aerospace, military, medicine and many subsystems in the transportation industry. [1]

\section{Accelerated testing}

To gain at least rough data on the properties of these new technologies in long-term use, there is generally just one solution: accelerated tests in adverse conditions.

These tests usually make the conditions even worse than expected in real use, in order to gain a margin of security and to obtain results faster. Of course, any such test depends heavily on assumptions that are made and on factors that are simulated, as it is impossible to make complex tests that accurately simulate the real world use.

Accelerated testing of electronic devices and components is specified by a wide field of norms. American military standards are especially useful, as they define a very wide set of operating conditions, test methods, etc.

\section{$2.1 \quad$ Specimens}

For the purposes of this experiment, several sets of experimental printed circuit boards were prepared. All boards utilized 0R0 SMD resistors (1206), but different mounting technology was used: two types of ECAs (Amepox AX12 and Amepox AX20), two types of leadfree solders (COBAR XM 3S and Kester EM907) and one type of $\mathrm{Sn}-\mathrm{Pb}$ solder (COBAR S62-GM5) were used. Only the two COBAR solders were examined.

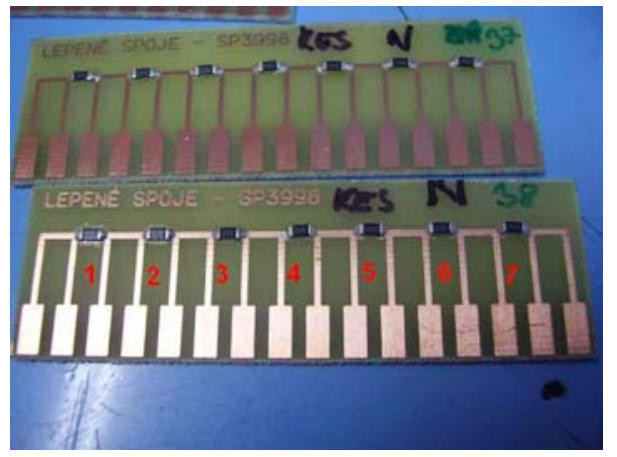

Fig. 1: Experimental circuit boards

\subsection{Thermal cycles}

The experiments performed by the authors were aimed at comparing leadfree solders and electrically conductive adhesives of various types under cyclic climatic stresses. Thanks to the available equipment, it was possible to perform three different sets of climatic shocks.

First experiment was aimed at rapid changes of outside temperature. The specimens suffered repeated transition shocks between $125^{\circ} \mathrm{C}$ dry heat and $-45^{\circ} \mathrm{C}$ cold. The dwell time at each of these temperatures was 
15 minutes - this setup ensured good heating/cooling of the soldered joints. Each specimen suffered 182 such shocks.

The temperature profile of these changes is shown in Figure 2.

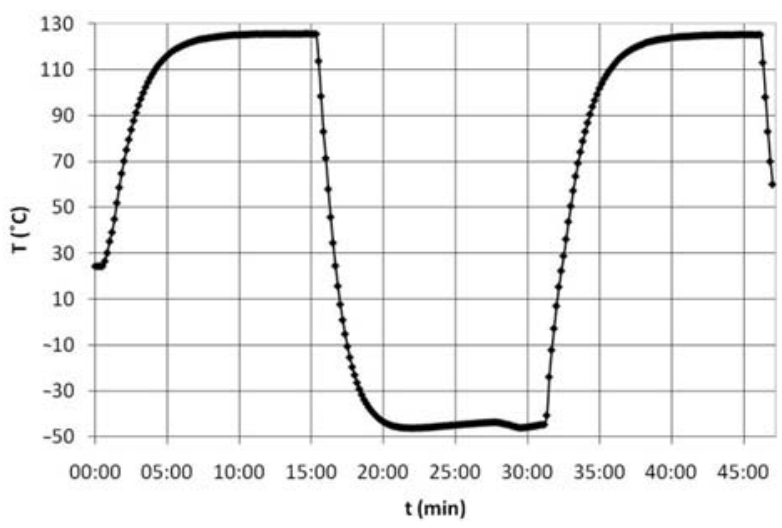

Fig. 2: Temperature profile of thermal shocks

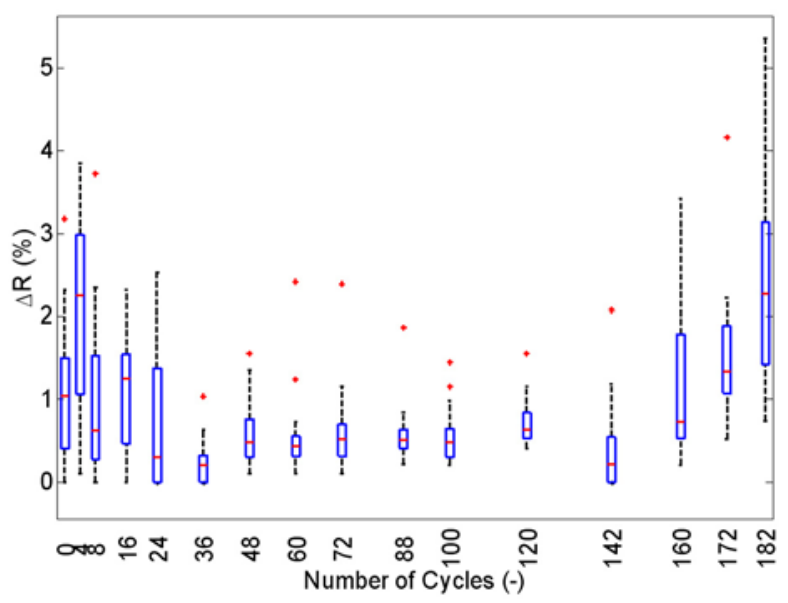

Fig. 3: Resistance change depending on thermal shocks for $\mathrm{Sn}-\mathrm{Pb}$ solder

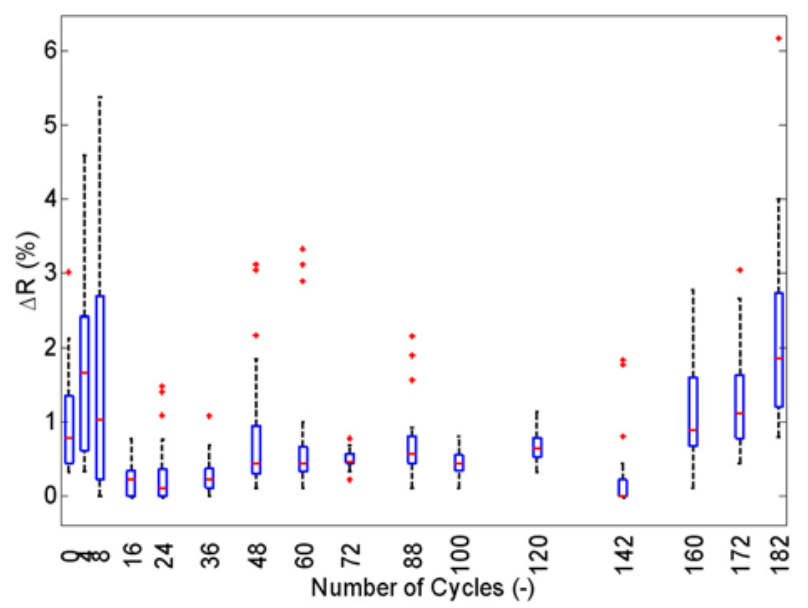

Fig. 4: Resistance change depending on thermal shocks for leadfree solder

Figures 3 and 4 allow a comparison of $\mathrm{Sn}-\mathrm{Pb}$ and leadfree solders subjected to this kind of fatigue. As shown in the graphs, the change in electrical resistance in both cases was minor, and it was impossible to determine any significant clear trend.

Thermal cycling produced no significant structural changes, apart from significant surface oxidation of the soldered joints. In contrast to the ECA experiments, no apparent cracks formed.

\subsection{Moist heat - dry heat cycles}

In this subset of experiments, the specimens were subjected to cyclic shocks between moist heat $\left(50{ }^{\circ} \mathrm{C}\right.$, $100 \%$ humidity) and dry heat $\left(125^{\circ} \mathrm{C}\right)$. As shown in Figure 5, the increase in electrical resistance is again inconclusive for leadfree solder, and the same applies to $\mathrm{Sn}-\mathrm{Pb}$ solder (not shown due to space constraints).

Due to nature of the test - it was necessary to dry the specimens before measuring - it was possible to obtain only a much more limited set of values.

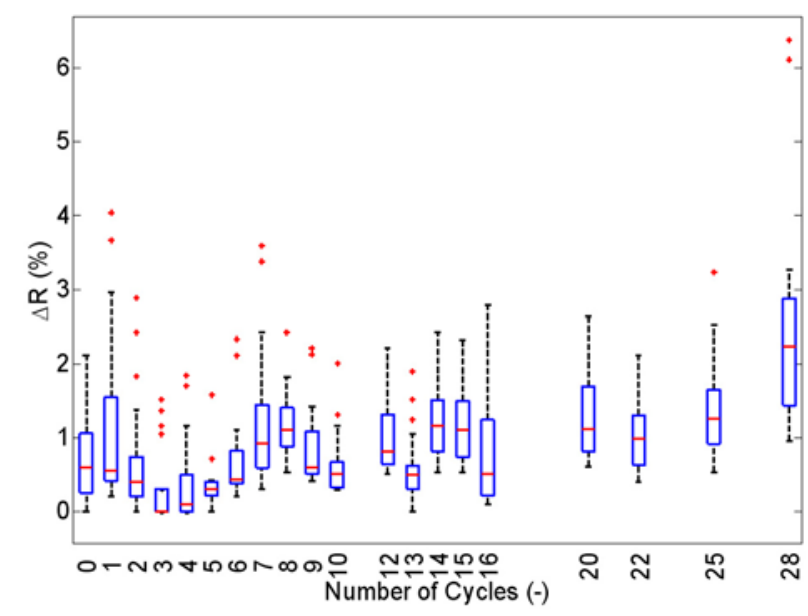

Fig. 5: Resistance change depending on moisture-heat shocks for $\mathrm{Sn}-\mathrm{Pb}$ solder

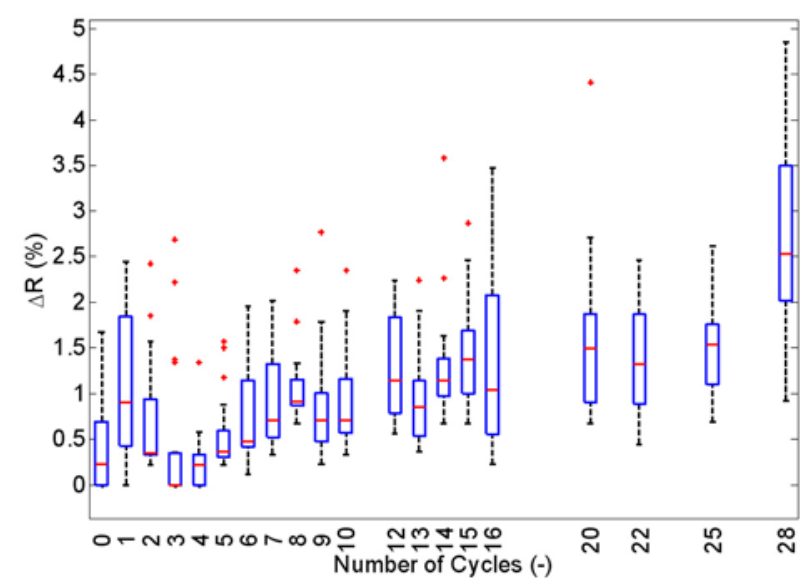

Fig. 6: Resistance change depending on moisture-heat shocks for leadfree solder

This type of climatic stress showed a significant increase in the extent and intensity of oxidation. As 
shown in Figure 7, the surface of the joint is covered with oxides. Unfortunately, as with 2.2 , no cracks were observed in the joints.

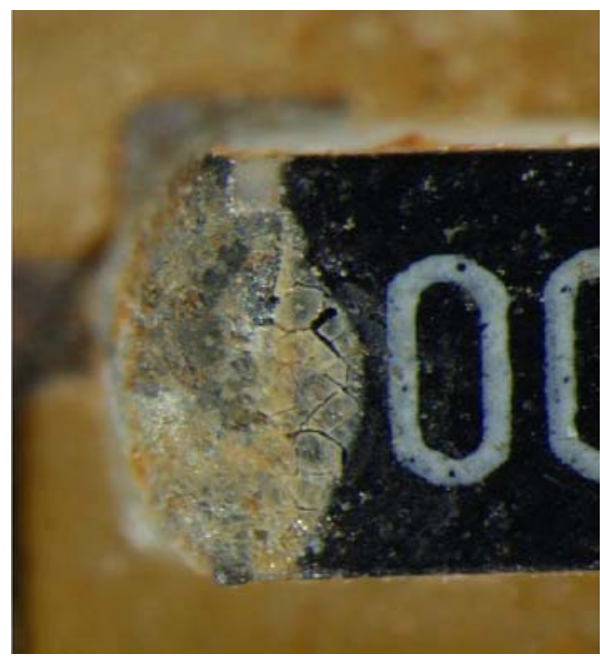

Fig. 7: Oxidation of the surface of a soldered joint after moisture-heat cycling

\subsection{Moist heat - cold cycles}

The last of the settings for climatic shocks utilized moist heat (see above) and cold. As with the other experiments, Figures 8 and 9 show that the electrical resistance of the soldered joints did not react significantly to climatic shocks, even in such adverse conditions. However, the surfaces of the joints again showed significant damage, as shown in Figure 10.

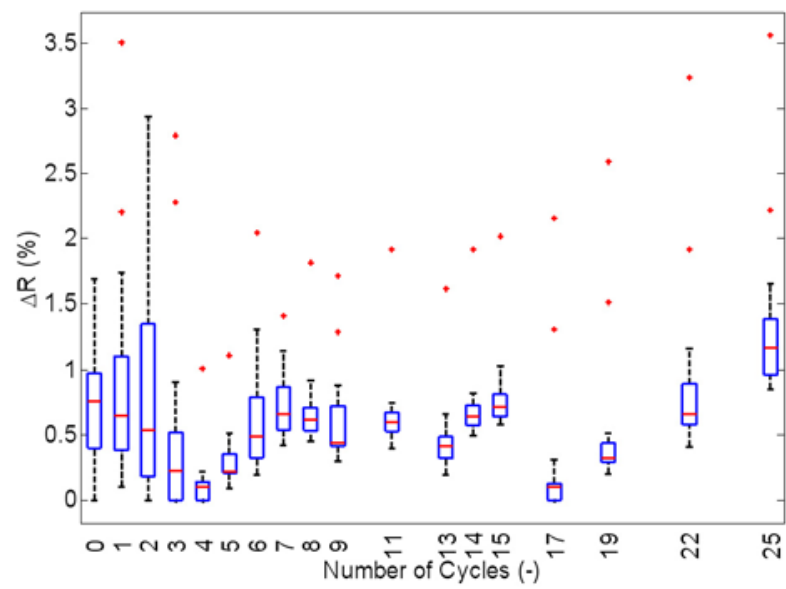

Fig. 8: Resistance change depending on moisture-cold shocks for $\mathrm{Sn}-\mathrm{Pb}$ solder

The degradation of the surface of the solder, as shown in Figure 10, resembles tin pest. Tin pest is a phase transformation of solid tin caused by low temperatures - it starts to demonstrate itself at roughly $13^{\circ} \mathrm{C}$, and the lower the temperature, the worse the tin pest. Tin pest has again attracted attention with the widespread use of leadfree solders.

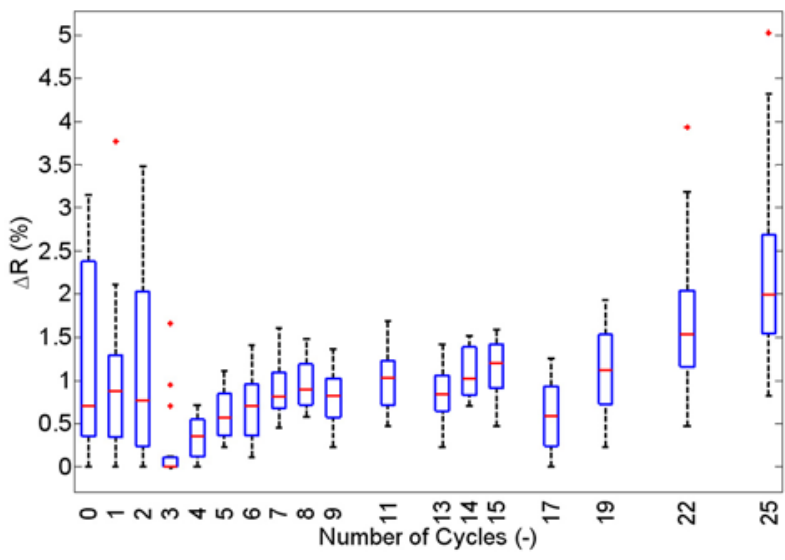

Fig. 9: Resistance change depending on moisture-cold shocks for leadfree solder

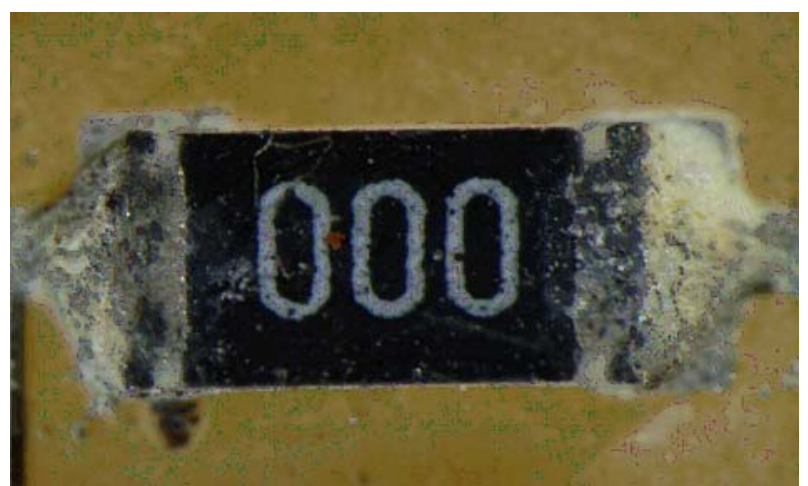

Fig. 10: Surface of leadfree solder after moist-cold cycles

Problems caused by tin pest have been observed on electronics such as cell phone base stations and other electronic devices located outdoors. One area where it struck unexpectedly was the ISAF mission in Afghanistan, where a number of armies (especially the US Army) used off-the-shelf portable computers manufactured with leadfree solders. [2]

\section{Conclusion}

The conclusions drawn from this research are, unfortunately, mostly negative. It has been shown that electrical resistance cannot be used to determine damage caused to soldered joints by climatic cycling, at least not in the extent that could realistically be performed in the laboratory belonging to the department.

However the results also show the possibility of a closer study of surface changes to the solder, especially aimed at low-temperature changes. The results from the round of experiments discussed in this article will be extended by obtaining quality cross-sections and examining them using electron microscopy.

\section{References}

[1] Mach, P., Skočil, V., Urbánek, J.: Montáž v elektronice: Pouzdření aktivních součástek, plošné 
spoje. 1. vyd. Praha : Vydavatelství ČVUT, 2001. 440 s. ISBN 80-01-02392-3.

[2] Lasky, R. C.: Tin Pest: A Forgotten Issue in Leadfree Soldering?, 2004 SMTA International Conference Proceedings, Chicago, IL, Sept. 26-30, 2004, p. 838-840.

\section{About the authors}

Marek TUČAN was born in Kladno, Czech Republic, in 1982. He graduated from the Faculty of Electrical Engineering in 2008, specializing in Electrotechnology, and has remained faithful to his alma mater. Currently he is a postgraduate student under the supervision of doc. Jan Urbánek, and is conducting research on the properties of leadfree solders. He is fluent in English and French, and is able to handle short technical texts and tables in Russian, German and Polish. Among a wide scale of his hobbies the most prominent is history studies and military studies, aviation and space technology.
Pavel ŽÁK was born in 1983. In 2006 he graduated from the bachelor degree program in Electrical Engineering and entered the Information Technology - Power Engineering master degree program at FEE-CTU in Prague. Two years later he graduated with a master's degree in electrotechnology. At present, he is studying a postgraduate doctoral degree program under the supervision of Assoc. Prof. Ivan Kudláček, Ph.D. He is fluent in French and English, and has a basic knowledge of German. His hobbies include electronics, photography, aviation, marine model making and fishkeeping. He works part-time in a private electrophysical laboratory.

\author{
Marek Tučan \\ Pavel Žák \\ E-mail: tucanm1@fel.cvut.cz, \\ zakpavel@fel.cvut.cz \\ Dept. of Electrotechnology \\ Faculty of Electrical Engineering \\ Czech Technical University \\ Technická 2, 16627 Praha, Czech Republic
}

